Edited by: M. Bull

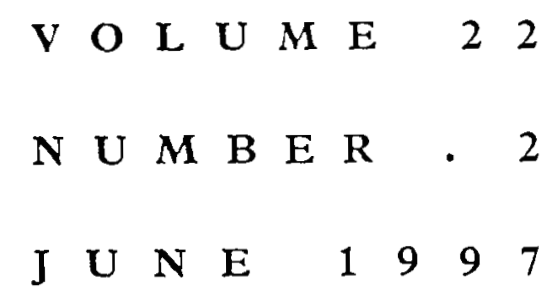
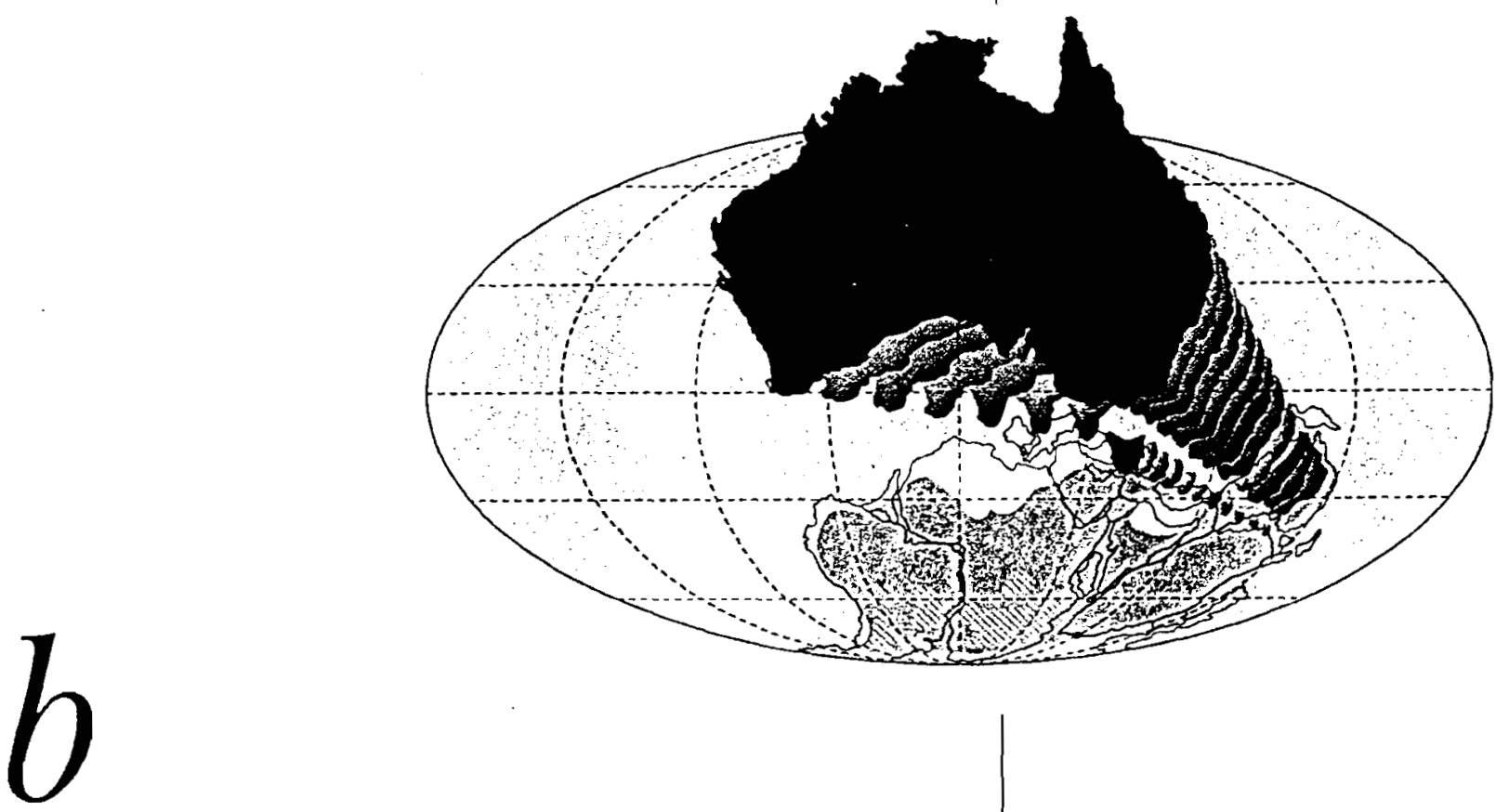

Blackwell 


\title{
Subcanopy gaps in temperate and tropical forests
}

\author{
JOSEPH H. CONNELL', MARGARET D. LOWMAN ${ }^{2}$ AND \\ IAN R. NOBLE ${ }^{3}$ \\ ${ }^{1}$ Department of Ecology, Evolution $\mathcal{E}$ Marine Biology, University of California, \\ Santa Barbara, CA 93106, USA, ${ }^{2}$ Marie Selby Botanical Gardens, Sarasota, \\ FL 34236, USA and ${ }^{3}$ Ecosy'stem Dynamics Group, Research School of Biological \\ Sciences, Australian National University, Canberra, ACT 0200, Australia
}

\begin{abstract}
We present a model of gaps in the vertical structure of forest vegetation. The traditional model of a forest gap assumes the existence of a 'hole' in the uppermost canopy layer, often extending down to near the ground. The present model extends the concept to gaps at any level, including those in lower layers below an intact canopy or subcanopy. It assumes that gaps at any level represent spaces with unused resources, especially favourable for plant growth and survival. Evidence from temperate and tropical forests indicates that gaps in the subcanopy and understorey layers below intact canopies are common, and that plants have higher growth rates in them than in non-gap sites. We also extend this model to below-ground gaps in the root zone.
\end{abstract}

Key words: below-ground gap, canopy gap, forests, light regime, soil resources, subcanopy gap, understorey gap.

\section{INTRODUCTION}

Gaps in vegetation are local sites where additional resources, both above- and below-ground, have become available due to the absence of a resident plant. As a consequence, the increased resources can allow neighbours or new recruits located in and around the gap to grow, survive and reproduce better than those outside it. In addition, gaps represent 'regeneration niches' (Grubb 1977), to which some species are assumed to have adapted as 'fugitives' from competition. The importance of gaps was first recognized in terrestrial vegetation (Watt 1947; Cousens 1974; Platt 1975; Whitmore 1975), but studies in other habitats (e.g. assemblages of any sessile organisms, including invertebrates such as corals, bryozoans etc.) have also indicated their importance (Dayton 1971; Reed \& Foster 1984; Connell \& Keough 1985; Sousa 1985).

However, recently some authors have suggested that the simple gap/non-gap dichotomy may be less useful in understanding community dynamics than a more complex classification of forest structure. For example, Brokaw and Scheiner (1989) stated, 'Results ... suggest the need to explore pervasive processes unrelated to discernible gaps'; while Connell (1989) stated, 'the selection that takes place beneath the closed canopy has a great influence on the suite of species available to take advantage of the short burst of light in a gap'. Lieberman et al. (1989) stated, 'considering forests as a Swiss

Accepred for publication October 1996. cheese of gaps and non-gaps does not even begin to do justice to the daunting complexity of real forests'. In this paper we attempt to deal with this complexity by expanding the traditional concept of gaps to include additional types not considered previously.

We propose the following general definition of a gap: 'a space temporarily left unoccupied in an assemblage of sessile organisms'. We include the word 'temporarily' in the definition because gaps will almost certainly be filled eventually by the growth of new colonists and/or survivors within and bordering the gap, unless further disturbance interrupts this process. This expectation is based upon the fact that a living individual uses local resources for maintenance, growth and reproduction, so that its death, in whole or part, releases some resources that can be used by its neighbours or new colonists as they fill the gap.

In this paper we consider only gaps in terrestrial vegetation, principally multilayered temperate and tropical forests. Our general definition of a forest gap is broader than Brokaw's (1982): 'a "hole" in the forest extending through all levels down to an average height of two m above ground', or Hubbell and Foster's (1986) definition of a gap as an opening in the uppermost canopy extending down to any height. Our definition includes these, but introduces additional types of gaps in leaf layers at intermediate or lower heights, with or without an opening in the canopy above. We first discuss these subcanopy gaps in the above-ground vegetation, then go on to discuss some theoretical ideas about gaps in the root zone. 


\section{A MODEL OF GAPS IN ABOVE-GROUND VEGETATION}

Consider a model forest with just three strata of leafy vegetation: canopy, subcanopy and understorey. In this model, there are eight possible combinations of the three leaf strata (Fig. 1). The definition of Brokaw (1982) recognizes only the complete gap with holes in all three strata (type 1; Fig. 1); that of Hubbell and Foster (1986) includes this rype and adds two more: a gap in the canopy alone, and a gap extending down through the subcanopy (types 5 and 2; Fig. 1). Our model adds four more types, involving the lower two strata, singly or in combination (types $3,4,6$ and 7; Fig. 1).

These different sorts of gaps could be created in at least two ways. First, the complete or partial death of one or more plants of any size could create any of these types. For example, the fall of a large canopy tree may smash all trees below it, creating a type 1 gap in all layers. However, if the same tree died standing, the loss of its leaves may create a type 5 gap in the canopy layer alone. Likewise, if a subcanopy or understorey tree died standing, this would create a type 6 or 7 gap, respectively. Second, the different rypes could occur at various stages during the filling of a type 1 gap. For example, such a gap could be filled from the bottom up, by the following sequence of gap types (shown in Fig. 1): type 1, then types 2, 5, 8, or other possible sequences. Alternatively; the gap could be filled in from the sides, if the crowns of canopy or subcanopy trees bordering the gap grew laterally into it; for example, the sequence could be: types $4,7,8$, or types $3,7,8$.

Type of gap Cross-section of gap T. CONPLETE GAP

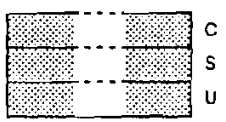

2. CANOPY AND GAP
SUBANO

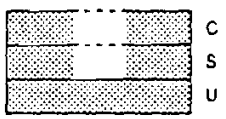

$$
3 .
$$


temperate mixed deciduous forest at $39^{\circ}$ latitude in the Appalachian mountains in the eastern United States. An analysis of these data using the model in Fig. 1 indicates that the proportions of the different types of gaps were very similar to those in the tropical forest we analysed in Queensland (Table 1). Thus 'subcanopy gaps' occupied the largest proportion of the area both in the two rainforests we studied and in the temperate forest studied by Parker (1995). In comparison, the classic 'complete gap' (type 1) was relatively rare in all three forests. Complete gaps are also rare in other rainforests; estimates usually range from 1 to $3 \%$ of the area (see review by Clark 1990).

The fifth bit of evidence comes from a study of the growth of seedlings and small saplings in the subtropical rainforest in Queensland described above. We

Table 1. Proportion of the surface area of forests comprised of different types of gaps

Percentage of ground area in each type of gap

\begin{tabular}{lcccc} 
Forest latitude & $\begin{array}{c}\text { Complete gap } \\
\text { in all } 3 \text { layers } \\
\text { Type I }\end{array}$ & $\begin{array}{c}\text { With gaps in only } \\
\text { canopy and/or } \\
\text { subcanopy layers } \\
\text { Types 2,3,5 }\end{array}$ & $\begin{array}{c}\text { Subcanopy and understorey } \\
\text { gaps beneath an intact } \\
\text { canopy layer } \\
\text { Types } 4,6,7\end{array}$ & $\begin{array}{c}\text { No gap } \\
\text { Type 8 }\end{array}$ \\
\hline Tropical rainforest, $17^{\circ} \mathrm{S}$ & 3 & 25 & 38 & 33 \\
Subtropical rainforest, $28^{\circ} \mathrm{S}$ & 2 & 14 & 48 & 36 \\
Temperate deciduous, $39^{\circ} \mathrm{N}$ & 3 & 26 & 43 & 28 \\
\hline
\end{tabular}

See Fig. 1 for illustrations of gap types. Height limits of layers: canopy $>20 \mathrm{~m}$, subcanopy 10-19.9 m, understory 2-9.9 m.

Table 2. Height of lowest leaf layer over saplings at a subtropical rainforest site

\begin{tabular}{|c|c|c|c|}
\hline \multirow[b]{2}{*}{ Family } & \multirow[b]{2}{*}{ Species } & \multicolumn{2}{|c|}{ Height to lowest leaf layer over sapling (m) } \\
\hline & & Fast-growing sapling & Slow-growing sapling \\
\hline Euphorbiaceae & Baloghia inophylla & 3.4 & 0.3 \\
\hline Eupomariaceae & Eupomatia laurina & 2.7 & 7.9 \\
\hline Lauraceae & Crytocarya obovata & 9.8 & $4.0^{3}$ \\
\hline Myrtaceae & Rhodomyrtus psidioides & 6.4 & 0.3 \\
\hline Proteaceae & Orites excelsa & 17.7 & 0.5 \\
\hline$"$ & Stenocarpus salignus & 14.6 & 1.5 \\
\hline$"$ & Stenocarpus sinuatus & 25.9 & 0.6 \\
\hline Rubiaceae & Randia benthamiana & 14.6 & 0.9 \\
\hline Rutaceae & Acronychia pubescens & 25.6 & 0.8 \\
\hline$"$ & $"$ & 17.5 & 2.4 \\
\hline$"$ & $"$ & 1.4 & $2.1^{2}$ \\
\hline$"$ & $"$ & 1.8 & $1.4^{2}$ \\
\hline$"$ & Euodia micrococca & 11.6 & 2.3 \\
\hline Sapindaceae & Ellatostachys nervosa & 9.1 & 0.9 \\
\hline$"$ & $"$ & 3.5 & 0.6 \\
\hline$"$ & $"$ & 1.7 & 0.1 \\
\hline$"$ & Guioa semiglauca & 11.3 & 0.6 \\
\hline$"$ & Mischocarpus pyriformis & 26.8 & $0.3^{\mathrm{b}}$ \\
\hline$"$ & $"$ & 9.5 & 11.3 \\
\hline$"$ & Sarcopteryx stipitata & 6.9 & $4.0^{\mathrm{b}}$ \\
\hline Saxifragaceae & Quintinia sieberi & 10.4 & 5.6 \\
\hline$"$ & $"$ & 5.5 & 4.9 \\
\hline Sterculiaceae & Argyrodendron actinophyllum & 8.4 & 1.1 \\
\hline$"$ & " & 4.0 & $1.5^{2}$ \\
\hline$"$ & $"$ & 1.4 & 0.9 \\
\hline Winteraceae & Tasmannia insipida & 22.6 & 2.6 \\
\hline Mean & & 10.5 & 2.3 \\
\hline SE & & 1.6 & 0.5 \\
\hline$N$ & & 26 & 26 \\
\hline $\begin{array}{l}\text { Paired } t \text {-test } \\
P\end{array}$ & & & $\begin{array}{l}4.76 \\
.001\end{array}$ \\
\hline
\end{tabular}

${ }^{2}$ More herbivore damage on the slow-grower; ${ }^{b}$ Slow-grower very close to a large tree. 
observed that, while most seedlings and saplings had grown very little over a 6 year period, some had grown appreciably; many of the fast-growers were not in 'complete gaps' as defined by Brokaw (1982). To discover the reasons for the fast growth outside complete gaps, we identified the 100 fastest-growing small saplings (0.3-2 $\mathrm{m}$ height at the start of the study), and in the field examined them for condition and local neighbour hood, recording proximity to larger trees, evidence of herbivory and distance to the nearest leaf layer above. As a control, we matched each fast-grower with a slowgrowing conspecific sapling that: (i) had grown more slowly during the study interval $(<25 \%$ of the growth rate of the fast-grower), (ii) was about the same size at the start of the interval (within $\pm 25 \%$ of the height of the fast-grower), and (iii) was located nearby $(<30 \mathrm{~m}$ apart). As we were interested in growth outside complete gaps, we eliminated any sapling that had occurred in such a gap during the 6 year period of measurement. We found 26 pairs of saplings that satisfied all these criteria.

Our survey indicated that the fast-growers tended to be located in sites with a greater distance to the first leaf layer above than was the case for the slow-growing member of the matched pair. In 17 of the 26 pairs, the fast-grower had at least twice the open space above it as the slow-grower; this difference was significant (paired $t$-test; Table 2). The other variables noted were apparently less important: we found only two saplings (both slow-growers) that were very close to larger trees (Table 2); and instances of obvious herbivory occurred in only four pairs, always with more leaf damage in the slow-grower. In sum, the fast-growers tended to be in subcanopy and/or understorey gaps (types 4,6 , or 7), with significantly more distance to the leaf layers above them than the slow-growers had.

We suggest that the mechanism producing this difference is the degree of obstruction of solar radiation arriving from various angles within the hemisphere of space centred on the seedling. Canham et al. (1990) have shown that beneath the canopy of multilayered forests in both tropical and temperate latitudes, most light arrives at the ground from low angles, further than $20^{\circ}$ away from the zenith. A low layer of leaves overhanging a seedling at a short distance above it will occlude more of the light that arrives from these low angles, than would the same leaf layer situated further above the same seedling. Therefore a gap in the understorey should allow more low-angle light to reach a seedling or small sapling than a gap in a site with an intact understorey layer of leaves. Canham ez al. (1990) noted that in a temperate Douglas fir-hemlock forest, a low subcanopy layer of hemlock probably occluded much of the light arriving from low angles.

These studies (Denslow et al. 1991; Brown \& Parker 1994; Parker 1995; Canham et al. 1990; Tables 1,2) suggest that (i) gaps in the subcanopy and/or under- storey layers of dense, multilayered forests (types 4,6 or 7) are more common than gaps that include the upper canopy layers (types 2, 3 or 5; see Table 1), and (ii) subcanopy gaps that include the understorey (rypes 4 or 7) probably allow as much or more light to reach seedlings and small saplings (which should promote their growth) than gaps that occur only in the canopy and/or subcanopy layers (types 2,5 or 6 ).

\section{BELOW-GROUND GAPS}

We have concentrated on the effect of changes in aboveground vegetation on the availability of light to smaller plants. However, there is strong evidence that, as well as the above-ground portions, many roots die in gaps. This should increase availability of soil resources in these 'below-ground gaps', analogous to the increase in light in above-ground gaps. For example, the biomass of fine roots per unit volume was significantly lower in type 1 gaps than in shaded understorey in a tropical rainforest (Sanford 1989, 1990) and in a temperate broad-leaved forest (Wilczynski \& Pickett 1993). The soil water content in samples from 0 to $15 \mathrm{~cm}$ depth was also higher in type 1 gaps than in shaded understorey in a tropical rainforest (Vitousek \& Denslow 1986). Seedling recruitment, growth and survival have been enhanced in below-ground gaps produced experimentally by trenching, in temperate forests and tree plantations (Fricke 1904; Toumey \& Kienholz 1931; Korstian \& Coile 1938; Lutz 1945; Shirley 1945; Horn 1985; Cristy 1986) but less so in tropical rainforests (Connell 1971; Fox 1973).

Given this evidence, we hypothesize that belowground gaps occur whenever a plant of any size dies, with the consequence that the soil resources formerly taken up by that plant become available to other plants in and near the gap. If this hypothesis is true, we suggest that the shorter plants (seedlings and saplings) in subcanopy and/or understorey gaps should have access to additional soil water and nutrients, as has been demonstrated for complete gaps in the studies referred to above. The reasoning behind this suggestion is that because seedlings and small saplings have shallow roots they will only have access to additional soil resources released by the death of shallow roots. As most trees, including those in the subcanopy and understorey, have shallow (as well as deep) roots, the fine-root biomass at shallow soil depths should be reduced below a recently dead medium-sized or a small tree, as it would below a large recently dead tree. If so, seedlings or small saplings in subcanopy gaps (types 4, 6 and 7; Fig. 1), should have access to additional soil water and nutrients.

\section{DISCUSSION}

Our aim in the models of above-ground vegetation (Fig. 1) is to focus attention on the role of gaps in the lower layers of forest vegetation, which usually have 
been considered only when the layers above them were missing. We argue that when a tree of any size dies, the resources (light and soil nutrients and water) that it formerly used will then be available to its neighbours, which should respond and fill the gap.

Our results (Table 2), and those of Canham et al. (1990), Denslow et al. (1991), and Brown and Parker (1994), suggest that a small plant in the shaded understorey of a dense, multilayered forest will receive more light, and probably grow and survive better, the greater the amount of unobstructed space it has in the hemisphere of space above it.

In regard to below-ground gaps, previous studies have shown that the fine-root biomass at shallow soil depths is reduced in complete gaps (tope 1; Fig. 1). We suggest that root biomass will also be reduced at shallow soil depths in subcanopy gaps beneath an intact canopy. Therefore, seedlings and small saplings, which have shallow roots, will have access to additional soil nutrients and water in these subcanopy gaps (tres 4,6 and 7; Fig. 1).

These ideas do not diminish the importance of the classic complete gap to the recruiment, growth and survival both of young stages of trees and of adults of subcanopy and understorey species. However, the proportion of area occupied by complete gaps is usually small, whereas subcanopy gaps, both in the rainforests studied here and in a temperate forest (Parker 1995), occupied a much larger proportion of the area. Therefore most seedlings, saplings and smaller understorey adults will spend the majority of their lives below an intact upper canopy layer, often in subcanopy and understorey gaps. Our aim here is to point out that, in addition to traditional complete gaps, the subcanopy gaps that exist beneath an intact upper canopy may also be important to the dynamics of broadleaved multilayered forests, because of their relative frequency, and because the resources they release are of particular importance to the success of seedlings and saplings, which are the age classes that determine the furure species composirion and diversity of these forests.

\section{ACKNOWLEDGEMENTS}

We thank the following people for comments on the manuscript: R. Black, A. Brooks, J. Casas, M. Connell, J. Denslow, S. Diehl, L. Goldwasser, P. Green, P. Grubb, S. Holbrook, J. Kastendiek, D. Lohse, E. McCauley; D. Meade, D. Metcalfe, C. Nadolny, G. Parker, W. Platt, P. Raimondi, D. Reed, S. Swank, S. Swarbrick, S. Schroeter, and C. Tyler. Many of the ideas are based on research supported by the National Science Foundation, most recently by grants DEB 92-20672 and DEB 95-03217.

\section{REFERENCES}

Brokaw N. V. L. (1982) The definition of a treefall gap and its effect on measures of forest dymanics. Biotropica 14, 158-60.
Brokaw N. V. L. \& Scheiner S. M. (1989) Species composition in gaps and strucrure of a tropical forest. Ecology 70, $538-41$

Brown M. J. \& Parker G. G. (1994) Canopy light transmittance in a chronosequence of mixed-species deciduous forests. Can. f. For. Res. 24, 1694-1703.

Canham C. D., Denslow J. S., Platr W. J., Runkle J. R., Spies T. A. \& White P. S. (1990) Light regimes beneath closed canopies and tree-fall gaps in temperate and tropical forests. Can. F. For. Res. 20, 620-31.

Clark D. B. (1990) The role of disturbance in the regeneration of neotropical moist forests. In: Reproductive Ecology of Tropical Forest Plants (eds K. S. Bawa \& M. Hadley) pp. 201-315. Man and The Biosphere Series, Vol. 7, Parthenon Publishing Group, Park Ridge, NJ.

Connell J. H. (1971) On the role of natural enemies in preventing competitive exclusion in some marine animals and in rain forest trees. In: Dynamics of Populations (eds P. J. den Boer \& G. R. Gradwell) pp. 298-312. Centre for Agricultural Publication and Documentation, Wageningen, The Netherlands.

Connell J. H. (1989) Some processes affecting the species composition in forest gaps. Ecology 70, 560-2.

Connell J. H., Tracey J. G. \& Webb L. J. (1984) Compensatory recruitment, growth and mortality as factors maintaining rain forest tree diversity. Ecol. Monogr. 54, 141-64.

Connell J. H. \& Keough M. J. (1985) Disturbance and patch dynamics of subtidal marine animals on hard substrata. In: The Ecology of Natural Disturbance and Patch Dynamics (eds S. T. A. Pickett \& P. S. White) pp. 125-51. Academic Press, New York, NY.

Cousens J. E. (1974) An Introducrion to Hoodland Ecology' Oliver and Boyd, Edinburgh, Scotland.

Cristy E. J. (1986) Effect of root competivion and shading on growth of suppressed western hemlock (Tsuga heterophylla). Vegetatio $65,21-8$.

Dayton P. K. (1971) Competition, disturbance and community organization: the provision and subsequent utilization of space in a rocky intertidal community. Ecol. Monogr. 41, $351-89$.

Denslow J. S., Newell E. \& Ellison A. M. (1991) The effect of understory palms and cyclanths on the grouth and survival of Inga seedlings. Biotropica 23, 225-34.

Fox J. E. D. (1973) Dipterocarp seedling behaviour in Sabah. Malaj'sian For, 36, 205-14.

Fricke K. (1904) 'Licht und Schattenholzarten': ein wissenschaftlich nicht begrundetes Dogma. Centralbl. f.d. gesame Fortwesen. 30, 315-25.

Grubb P. J. (1977) The maintenance of species-richness in plant communities: the importance of the regeneration niche. Biol. Rev. 52, 107-45.

Horn J. C. (1985) Responses of understory tree seedlings to trenching. Am. Midl. Nautr. 114, 252-8.

Hubbell S. F. \& Foster R. B. (1986) Canopy gaps and the dynamics of a neotropical forest. In: Plan Ecology (ed. M. J. Crawley) pp. 77-96. Blackwell Science, Oxford.

Korstian C. F. \& Coile T. S. (1938) Plant Competition in Forest Stands. Duke University, School of Forestry Bull. 3, Durham, NC.

Lieberman M., Lieberman D. \& Peralta R. (1989) Forests are not just swiss cheese: canopy stereogeometry of non-gaps in tropical forests. Ecology 70, 550-5.

Lutz H. J. (1945) Vegetation on a trenched plot rwenty-one years after establishment. Ecology 26, 200-2.

Parker G. G. (1995) Structure and microclimate of forest 
canopies. In: Forest Conopies (eds M. D. Lowman \& N. Nadkarni) pp. 73-98. Academic Press, San Diego, CA.

Platt W. J. (1975) The colonization and formation of equilibrium plant species associations on badger disturbances in a tall-grass prairie. Ecol. Monogr. 45, 285-305.

Reed D. C. \& Foster M. S. (1984) The effects of canopy shading on algal recruitment and growth in a giant kelp forest. Ecology 65, 937-48.

Sanford R. L. (1989) Fine root biomass under a tropical forest light gap opening in Costa Rica. J. Trop. Ecol. 5, 251-6.

Sanford R. L. (1990) Fine root biomass under light gap openings in an Amazonian rain forest. Oecologia 83, 541-5.

Shirley H. L. (1945) Reproduction of upland conifers in the lake states as affected by root competition and light. Am. Mizll. Nat. 33, 537-612.
Sousa W. P. (1985) Disturbance and patch dynamics on rocky intertidal shores. In: The Ecology of Natural Disturbance and Patch Dymamics (eds S. T. A. Pickett \& P. S. White) pp. 101-24. Academic Press, New York, NY.

Toumey J. W. \& Kienholz R (1931) Trenched plots under forest canopies. Bull. Yale Univ. School For. 30, 1-31.

Vitousek P. M. \& Densiow J. S. (1986) Nirrogen and phosphorous availability in treefall gaps of a lowland tropical rainforest. F. Ecol. 74, 1167-78.

Watt A. S. (1947) Pattern and process in the plant community. 7. Ecol. $35,1-22$.

Whimore T. C. (1975) Tropical Rain Foresis of the Far East. Clarendon Press, Oxford.

Wilczynski C. J. \& Pickett S. T. A. (1993) Fine root biomass within experimental canopy gaps: evidence for a belowground gap. f. Veg. Sci. 4, 571-4. 